\title{
Design of a novel solar thermal collector using a multi-criteria
}

\section{decision-making methodology}

\author{
J. D. Nixon ${ }^{a^{*}}$ P. K. Dey ${ }^{b}$ and P. A. Davies ${ }^{a}$ \\ ${ }^{a}$ Sustainable Environment Research Group, School of Engineering and Applied Science \\ Aston University, Aston Triangle, Birmingham, B4 7ET, UK \\ ${ }^{\mathrm{b}}$ Aston Business School, Aston University, Aston Triangle, Birmingham, B4 7ET, UK \\ *corresponding author, e-mail: nixonjd1@aston.ac.uk, Tel +44 1212043663
}

\begin{abstract}
Three novel solar thermal collector concepts derived from the linear Fresnel reflector (LFR) are developed and evaluated through a multi-criteria decision-making methodology, comprising the following techniques: Quality Function Deployment (QFD), the Analytical Hierarchy Process (AHP) and the Pugh selection matrix. Criteria are specified by technical and customer requirements gathered from Gujarat, India. The concepts are compared to a standard LFR for reference, and as a result, a novel 'Elevation Linear Fresnel Reflector' (ELFR) concept using elevating mirrors is selected. A detailed version of this concept is proposed and compared against two standard LFR configurations, one using constant and the other using variable horizontal mirror spacing. Annual performance is analysed for a typical meteorological year. Financial assessment is made through the construction of a prototype. The novel LFR has an annual optical efficiency of $49 \%$ and increases exergy by $13-23 \%$. Operational hours above a target temperature of $300^{\circ} \mathrm{C}$ are increased by $9-24 \%$. A $17 \%$ reduction in land usage is also achievable. However, the ELFR suffers from additional complexity and a 16-28\% increase in capital cost. It is concluded that this novel design is particularly promising for industrial applications and locations with restricted land availability or high land costs. The decision analysis methodology adopted is considered to have a wider potential for applications in the fields of renewable energy and sustainable design.
\end{abstract}

Keywords:

Solar thermal; Linear Fresnel reflector (LFR); Analytical hierarchy process (AHP); Quality function deployment (QFD); Pugh selection matrix; Multi-criteria decision-making (MCDM). 


\begin{tabular}{|c|c|}
\hline \multicolumn{2}{|c|}{ Nomenclature } \\
\hline AHP & Analytical hierarchy process \\
\hline$E L F R$ & Elevation Linear Fresnel Reflector \\
\hline$H o Q$ & House of quality \\
\hline H-constant & Horizontal-constant mirror spacing arrangement \\
\hline H-variable & Horizontal-variable mirror spacing arrangement \\
\hline$I A M$ & Incident angle modifier \\
\hline$e b_{n}$ & Elevation required to remove blocking of an $n^{\text {th }}$ element (m) \\
\hline$e s_{n}$ & Elevation required to remove shadowing of an $\mathrm{n}^{\text {th }}$ element $(\mathrm{m})$ \\
\hline$E_{x, \text { out }}$ & Exergy per collector aperture (maximum available power output) $\left(\mathrm{W} / \mathrm{m}^{2}\right)$ \\
\hline$f_{m}$ & Final overall weighting (-) \\
\hline$g_{m}$ & Customer requirement importance (-) \\
\hline$h$ & Receiver height (m) \\
\hline$Q$ & Net heat transfer to receiver's absorbing target (W) \\
\hline$Q_{I n} *$ & Heat transferred in $(\mathrm{W})$ \\
\hline$Q_{\text {Loss }}$ & Heat loss (W) \\
\hline$Q_{n}$ & Distance of an $\mathrm{n}^{\text {th }}$ mirror element from receiver $(\mathrm{m})$ \\
\hline$r_{m n}$ & Technical and customer requirement relationship score (-) \\
\hline$S_{n}$ & Shift or gap between mirror elements (m) \\
\hline$T_{a}$ & Ambient temperature $(\mathrm{K})$ \\
\hline$t_{n}$ & Technical priority (-) \\
\hline$T_{r}$ & Surface temperature of receiver's absorbing target $(\mathrm{K})$ \\
\hline$T_{r, \max }$ & Stagnation temperature (maximum temperature of receiver) $(\mathrm{K})$ \\
\hline$u_{m}$ & Improvement factor (-) \\
\hline$U_{L}$ & Heat loss coefficient $\left(\mathrm{W} / \mathrm{m}^{2} \mathrm{~K}\right)$ \\
\hline$W$ & Width of mirror elements (m) \\
\hline \multicolumn{2}{|c|}{ Greek Symbols } \\
\hline$\eta_{o}(0=\theta)$ & Optical efficiency at normal incidence \\
\hline$\eta_{\text {Shadow }}$ & Shadow efficiency \\
\hline$\eta_{\text {Blocking }}$ & Blocking efficiency \\
\hline$\theta_{l}$ & Angle in the longitudinal plane \\
\hline$\theta_{n}$ & Slope angle of an $\mathrm{n}^{\text {th }}$ mirror element \\
\hline$\theta_{p}$ & Profile angle of the sun \\
\hline$\theta_{t}$ & Angle in the transversal plane \\
\hline
\end{tabular}




\section{Introduction}

Since initial attempts to convert solar energy for the purpose of steam generation in the mid $19^{\text {th }}$ century (Kalogirou, 2004), only comparatively recently has there been a renewed interest in concentrating solar power (CSP) technologies. A CSP technology is formed from a concentrator and receiver assembly (Duffie and Beckman, 2006). The concentrator usually comprises mirrors to focus solar radiation onto a receiver. The receiver consists of an absorbing target to transfer concentrated energy, typically, to a heat transfer fluid. A range of different solar collectors with varying concentrator and receiver configurations is available on the market today; however, their designs have remained relatively unchanged since their conception.

The solar thermal collector which forms the focus of this paper is the linear Fresnel reflector (LFR), also known as the linear Fresnel collector (LFC). The LFR is considered to be particularly promising among CSP technologies as it benefits from a relatively simple and inexpensive design. In comparison to the more commonly implemented parabolic trough collector (PTC), which uses large parabolically shaped reflectors and a moving receiver, the LFR employs long, thin, low profile mirror elements, spaced horizontally and located close to the ground at vary distances from a central tower, thus minimising structural requirements and wind loads. Located at the top of the receiver tower is a fixed absorber, therefore removing the need for flexible high pressure pipe lines (Figure 1). Yet, as the LFR has less energy capture than the PTC and other CSP technologies, the need for improvements is still considered to be significant, particularly in raising the annual optical efficiency (Morin et al.). 


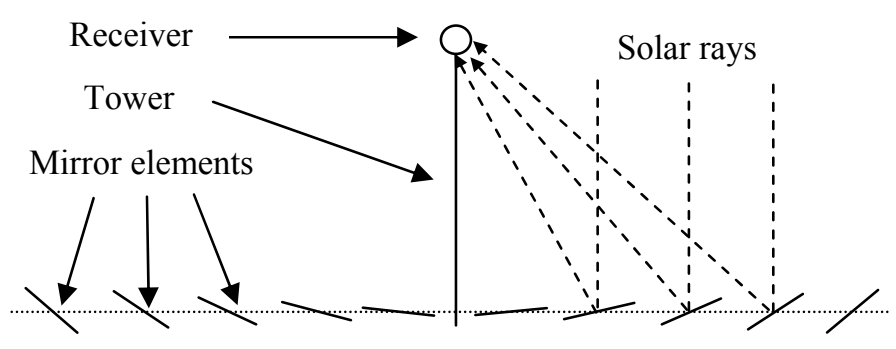

Figure 1: Schematic of a linear Fresnel reflector

The LFR principle was first developed by Baum et al. in 1957, and later applied by Giorgio Francia in 1961, who designed both linear and two-axis tracking Fresnel reflectors (Baum et al., 1957; Francia, 1968; Kalogirou, 2004). In 1979 a large scale project was initiated by the U.S Department of Energy for a 10 MWe and 100 MWe power plant during the oil crisis, but these never came to fruition due to a lack of funding (Kalogirou and Knovel, 2009). In 1991 the Israeli Paz company constructed a LFR at the Ben-Gurion Solar Electricity Technologies Test Centre; however, due to construction difficulties resulting optical efficiencies were very low (Feuermann, 1993). A new variant of the LFR termed the compact linear Fresnel reflector (CLFR) was initially proposed in 1993 at the University of Sydney. It used interleaving mirrors to focus sunlight onto multiple receiver towers (Mills, 2003; Mills and Morrison, 2000). In 2001 a Belgian company, Solarmundo, installed a $2500 \mathrm{~m}^{2}$ LFR prototype in Liege (Facão and Oliveira, 2011). Solarmundo later merged with the Solar Power Group, Germany, who constructed Fresdemo, a large pilot LFR system at the Plataforma Solar de Almería (P.S.A) in Spain, which was tested until 2008 (Bernhard et al., 2008a; Bernhard et al., 2008b; P.S.A, 2007). Since 2005 several LFRs have been constructed for industrial process heat applications and solar cooling in various locations across the USA and Europe, including the towns of Freiburg, Bergamo, Grombalia, and Sevilla (SolarPACES, 2008). Founded in 2006, Novatec Solar has recently development the world's first commercial LFR power plant, Puerto Errado 1 (PE 1), a 1.4 MW power plant that 
commenced selling power to the Spanish grid in March 2009. Puerto Errado 2, a 30 MW power plant has also begun construction in Murcia, Spain (Novatec, 2012). An extension of the CLFR design, termed 'etendue-matched', was proposed in 2010 (Chaves and CollaresPereira, 2010). Also in 2010 Industrial Solar, previously Mirroxx, built a $1408 \mathrm{~m}^{2}$ aperture area LFR for cooling of a 500 seat showcase stadium for Qatar's 2020 FIFA World Cup bid (Zahler et al., 2011). In 2011 Novatec Solar and Avera claimed that superheated steam at 450 ${ }^{\circ} \mathrm{C}$ through direct steam generation had been achieved in their LFR systems (Conlon, 2011; Mertins et al., 2011).

A major difficulty with the LFR is shading and blocking from adjacent mirror elements which reduces annual optical efficiency. Increasing the spacing between mirrors or height of the receiver tower helps to reduce these effects, but can increase land usage and costs. Optimisation of the LFR mirror spacing arrangement to maximise power output whilst minimising capital costs has been analysed in a cost-exergy study (Nixon and Davies, 2011). Optimisations of the LFR performance through varying the mirror width, shape, spacing, and number of mirror elements have also been reported (Barale et al., 2010; Chaves and CollaresPereira, 2010; Häberle, 2004; Häberle et al., 2002; Morin et al., 2008; Singh et al., 1999; Singh et al., 2010b; Sootha and Negi, 1994; Velázquez et al., 2010). This paper differs from those earlier studies in that novel LFR concepts, which do not necessarily conform to the standard LFR design, are developed and compared.

To arrive at these novel concepts, structured design methods are used, in particular Quality Function Deployment (QFD). QFD originated in the late 1960s and early 1970s in Japan and since then has grown in popularity for use in a number of industries including automotive, software development, steel and electronics (Chan and $\mathrm{Wu}, 2002$ ). QFD is a method that 
enables user demands to be transformed into design quality, priorities and targets (Akao, 1990). Researchers have suggested the use of QFD to ensure environmental awareness in product design (Masui et al., 2003) and for market strategy decision making for new housing developments (Dikmen et al., 2005). More recently QFD has been applied to the design of building integrated photovoltaic systems (Paul et al., 2008). So far, however, there have been very few (if any) references to the use of QFD in the field of solar thermal energy.

The primary and most significant tool in QFD is the 'House of Quality' (HoQ), which translates customer requirements into engineering characteristics i.e. technical requirements. A step by step illustrative application and example of the HoQ is given by (Chan and $\mathrm{Wu}$, 2005). These requirements are commonly obtained through interviews, surveys and MultiCriteria Decision-Making methods (MCDM). Approaches integrating QFD with decisionmaking methods such as the Analytical Hierarchy Process (AHP), goal programming and the Analytic Network Process (ANP) have been demonstrated in areas such as product planning (Karsak et al., 2003) and strategic marketing (Min Hua Lu, 1994). The AHP is a particularly popular MCDM method (Pohekar and Ramachandran, 2004). It breaks complex decision problems down into manageable sub-problems and provides a structured approach to analysing quantitative and qualitative data in pair-wise comparison matrices. A number of publications combining AHP and QFD for product design and selection are reviewed by Ho (2008). Other decision methodologies have also been integrated with QFD to further enhance concept selection. The Pugh matrix is a systematic process for the quick selection of a 'best' concept, and is commonly used in engineering decision making to score new design concepts against a baseline design. Individual design criteria are simply rated as better or worse for each new concept; the design with the highest score is then considered the best to pursue. QFD provides an objective approach to assigning an importance to the selection criteria. A 
joint US Air Force/NASA program to produce a heavy lift launch vehicle used the Pugh concept selection matrix with QFD for the selection of a new fuel turbo pump, comparing two different designs with a baseline concept (Butler, 1993)..

In the field of sustainable energy and manufacturing, several authors have used MCDM tools for system selection and cleaner production: Lozano-Minguez et al. (2011) used a MCDM technique to assess alternative support structures for offshore wind turbine installations; Cavallaro (2009) demonstrated an MCDM method to assess and compare alternative CSP systems; Kosoric et al. (2011) and Cavallaro (2010) have used MCDM methods for design, development and technology selection for Photovoltaics (PV); Ghadimi et al. (2012) proposed a fuzzy AHP method for product sustainability assessment for the automotive industry, and Myllyviita et al. (2012) combined MCDM with Life Cycle Assessment (LCA) to evaluate the environmental impact of biomass production. Methods such as QFD, AHP and the Pugh matrix are well documented in the literature and are therefore used here without further detailed background explanations (Akao, 1990; Pugh, 1991; Saaty, 2008).

The aim of this paper is to develop a novel LFR and thus improve on the standard LFR design in response to customer (and not purely technical) requirements. For the purpose of demonstrating the research methodology adopted, the region of Gujarat, India, has been chosen as a case study given the region's energy poverty and abundance of solar energy which is vastly underutilised. The objectives to accomplish this are as follows:

1. Using a multi-criteria decision-making methodology (QFD, AHP and Pugh), develop and select a novel LFR concept based on requirements (i.e. criteria) arising in Gujarat, 
India. Analyse the technical performance of a detailed design of the selected concept and an equivalent standard LFR design for comparison.

2. Construct a prototype of the novel LFR design to establish monetary values for comparison to standard design.

3. Evaluate the benefits and drawbacks of the novel design compared to the standard design, with reference to original customer and technical requirements.

4. Evaluate the effectiveness of the decision-making method in terms of incorporating customer and technical requirements, thus improving total quality.

The following section outlines a methodology that has been developed to achieve these objectives. Section 3 describes the creation of a house of quality matrix. In section 4, several novel LFR concepts are proposed and ranked in order of preference. The most preferred concept is finalised and analysed in detail in Sections 5 and 6. The paper concludes by discussing the developed methodology and implications and benefits of the new LFR design.

\section{Methodology}

The methodology used to reach these objectives will now be outlined.

\section{(i) Construction of the House of Quality:}

As in all QFD approaches, the customer requirements (WHATs i.e. what the customer wants) are collected for use in the HoQ. In this paper results from an AHP study, to identify the best CSP technology for Gujarat, India, are used to generate WHATs and their importance. Technical requirements (HOWs) for how the WHATs will be satisfied are also determined. The main outputs from the completed HoQ are technical priorities (weightings) for each 
HOW for the design of a novel LFR. Technical targets, limits and difficulties are also specified to develop product specifications.

\section{(ii) Concept development and selection:}

Three concepts for a novel LFR are developed. A Pugh matrix is completed by scoring the technical requirements as better or worse in each concept in comparison to a reference baseline LFR design. To arrive at a final overall ranking, the HoQ technical priorities are assigned to the Pugh matrix and the LFR design with the highest total score is selected.

\section{(iii) Finalized design of selected concept:}

A detailed design of the selected novel LFR concept is developed, while targets and limits are maintained based on those specified in the HoQ.

\section{(iv) Detailed analysis of selected LFR with standard design:}

The novel design is analysed through the use of ray-tracing to enable annual performance to be predicted over a typical meteorological year (TMY) for the region of Gujarat, India. Performance results include exergy per total mirror area, operational hours above a target operating temperature, net heat transfer to receiver and annual optical efficiency. The annual performances of two standard LFRs are also analysed for comparison. Financial results are determined through the construction of a prototype; and upper and lower land costs are researched for Gujarat. Capital costs and achievable cost per exergy among the final designs are evaluated and compared. 


\section{Construction of the House of Quality}

The customer requirements were extracted from importance weightings attributed by a panel of solar energy specialists working at the Solar Energy Centre in Delhi, India. This panel was convened for an earlier AHP study, which was reported by the authors in Ref. (Nixon et al., 2010). The panel weighted a series of technical, financial and environmental criteria applicable to the selection of the preferred CSP technology for use in India, and a pair-wise comparison matrix was completed to arrive at individual relative weightings (Figure 2). Criteria from the aforementioned AHP study that relate to WHAT the customers want were identified as ease of operation and high heat quality, which relate directly to use of standard parts and a high concentration ratio, reliability, land usage, cost of operations and capital cost. The relative weightings were used to assign a low (1), medium (3), and high (9) importance, $g_{m}$, to the WHATs, $W_{m}$, (Table 1). The technical requirements provided from the AHP results were expanded to include additional HOWs, $H_{n}$, deemed necessary for the design of a novel solar collector for India. An additional input to the HoQ was included to reflect an improvement factor, $u_{m}$, given by the ratio of the 'future product' rating, $a_{m}$, to 'current product' rating, $x_{m}$. A standard LFR was scored against the customer requirements, and compared to a target score for a novel design. A final overall weighting, $f_{m}$, was formed from the product of the customer's importance score and the design improvement factor.

Table 1: Customer requirements and their importance for a solar collector in India, established from an AHP study.

\begin{tabular}{lc} 
Customer Requirements & Customer importance \\
\hline Ease of Operation/Set-up & 3 \\
High Quality of Heat & 3 \\
Reliability & 9 \\
Land Usage & 9 \\
Cost of O\&M & 9 \\
Capital Cost & 9 \\
\hline
\end{tabular}




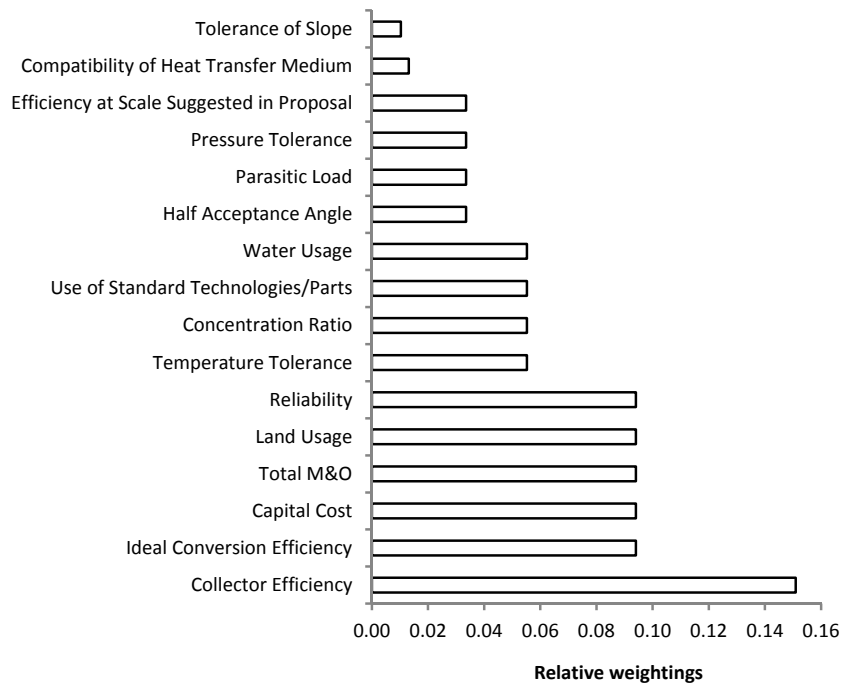

Figure 2: Weightings attributed to by an expert panel for technical, financial and environmental criteria in the selection of a solar thermal collector for India, using the Analytical Hierarchy Process (Nixon et al., 2010).

$f_{m}=g_{m} \cdot u_{m}$

To complete the HoQ relationship matrix, each HOW was scored against each WHAT on whether there was a weak (1), medium (3), or strong (9) relationship. The correlation matrix was omitted for simplicity. The importance, $t_{n}$, of each technical requirement was established by multiplication of each value in the relationship matrix, $r_{m n}$, by the respective overall weighting and totalling the scores for each technical requirement (Chan and $\mathrm{Wu}, 2005)$. $\mathrm{A}$ relative technical priority was established through normalisation. The completed HoQ included a target or limit and a technical difficulty for each HOW (see Figure 3).

$t_{n}=\sum_{m=1}^{M} f_{m} \cdot r_{m n}, \quad n=1,2 \ldots, N$

The HoQ identified the most important customer requirement to be land usage with an overall weighting of 14 , followed by the capital cost with a weighting of 6.8 . Ease of operation was 
found to be the least important customer requirement with a score of 1.8. The technical priorities revealed the cost per exergy to be the most important technical requirement with an $11 \%$ priority. With a priority of $7 \%$ the following technical requirements were ranked in second: reflectivity of the mirror elements, accurate tracking, half acceptance angle and concentration ratio. 


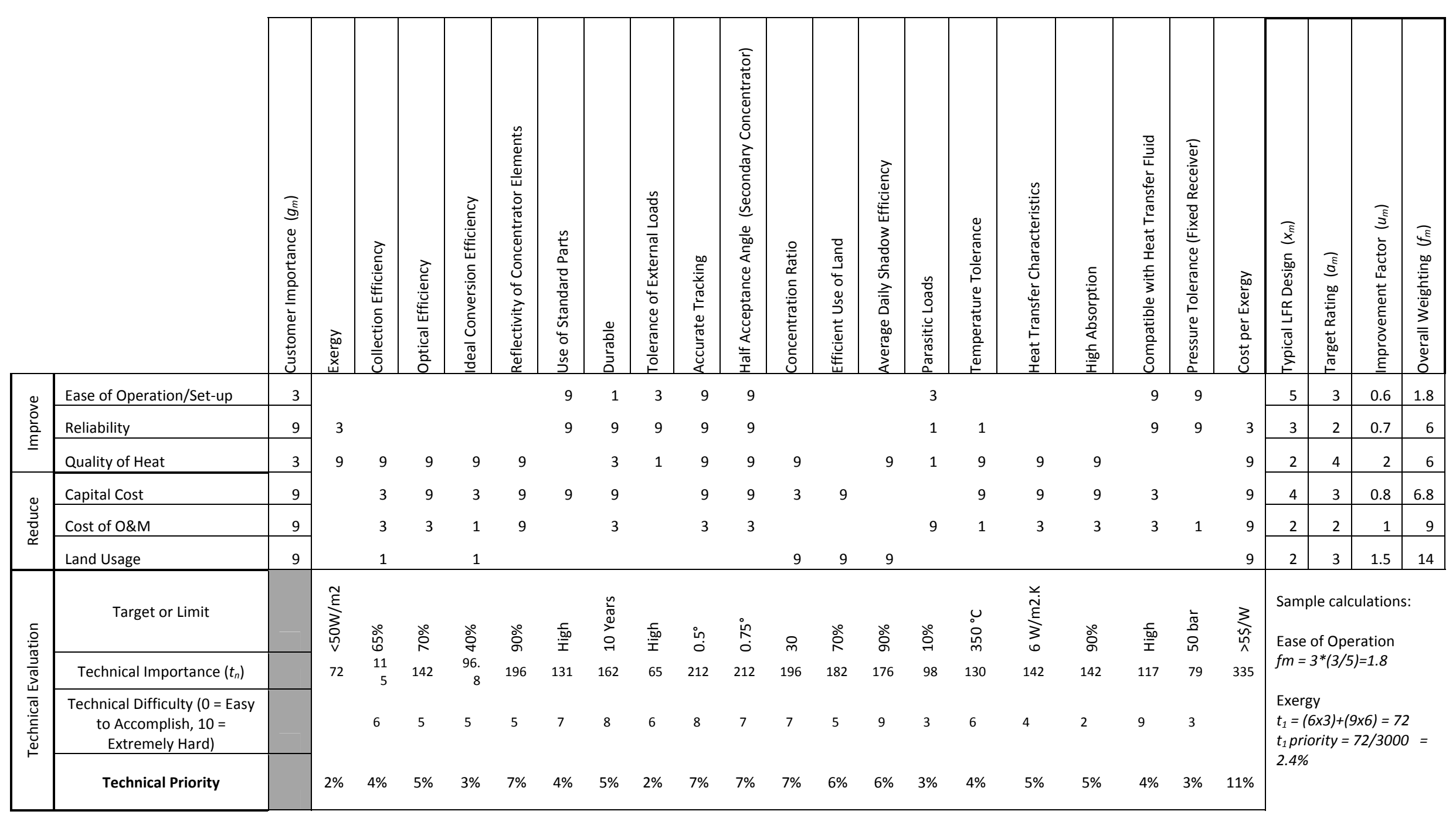

Figure 3: House of Quality constructed for the design of a novel LFR for India 


\section{Concept development and selection}

Three LFR concepts, Circular, Parabolic and Elevation, were consequently developed taking into account the customer and technical requirements and their weightings. Each LFR concept comprised a concentrator, formed from mirror elements, focusing on a fixed insulated target (the design traits typifying an LFR). Schematics of the three concepts and a standard LFR design (Horizontal) used as a baseline are shown in Figure 4a-d, which distinguishes the tracking method and element location in each case. A Pugh selection matrix was used to compare the novel LFR concepts in comparison to Horizontal. In the matrix concepts were scored against each technical requirement as better ' 1 ', even ' 0 ', or worse '-1'. Each score was then multiplied by the corresponding technical priority and totalled to provide a final weighted ranking. Among the alternatives the 'Elevation' concept, henceforth referred to concisely as the Elevation Linear Fresnel Reflector (ELFR), received the highest weighted ranking (see Table 2).

(a)

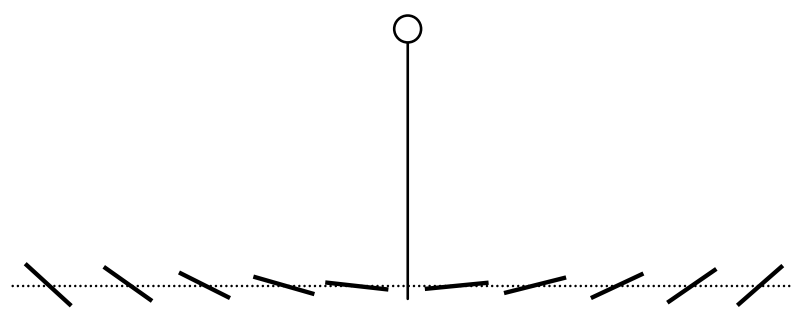

(b)

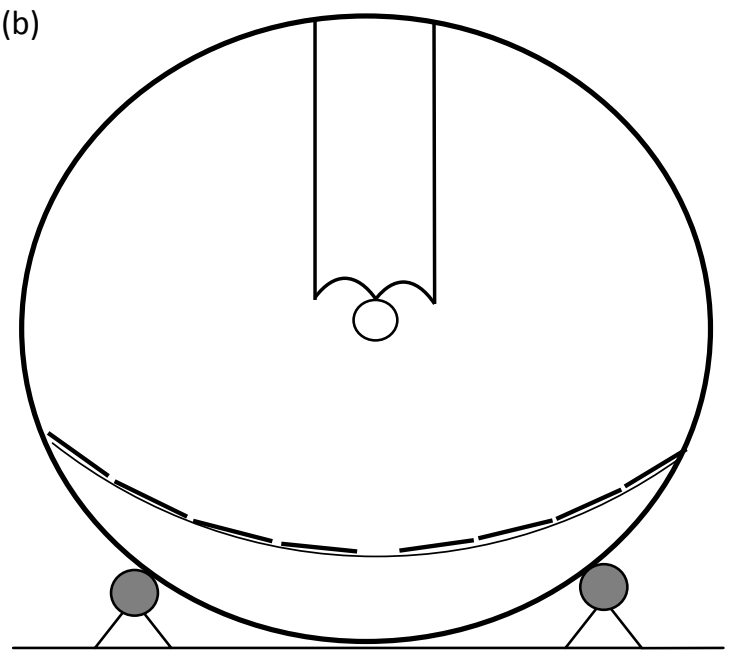

(c)

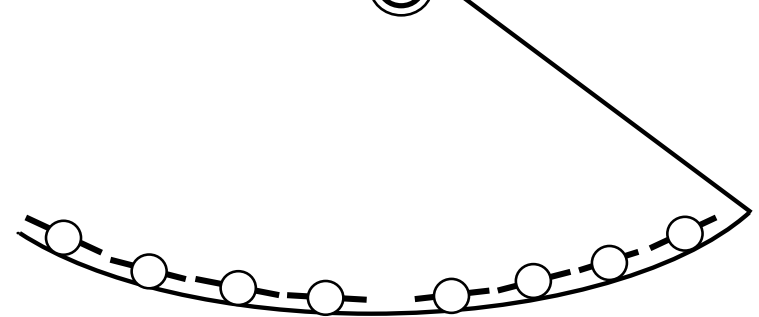

(d)

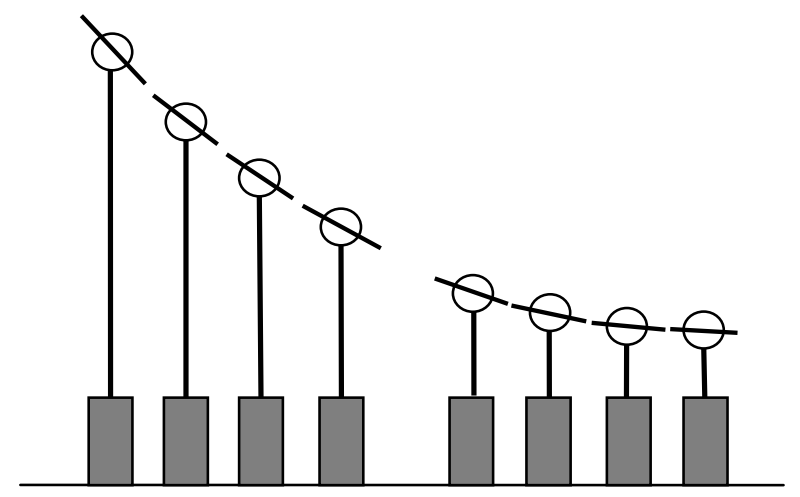


Figure 4a-d: Reference LFR concept (a) Horizontal - horizontal rotating elements. LFR concepts (b) Circular elements located along parabola rotating in a circular wheel, (c) Parabolic - rotating elements placed along parabolic path and (d) Elevation - rotating and elevating elements.

Table 2: Pugh concept selection matrix for a novel LFR. The concept Elevation (ELFR) obtained the highest final weighted ranking.

\begin{tabular}{|c|c|c|c|c|c|}
\hline Technical Requirements & $\begin{array}{l}\text { Technical } \\
\text { Priorities } \\
\end{array}$ & $\begin{array}{l}\text { Horizontal } \\
\text { (a) }\end{array}$ & $\begin{array}{c}\text { Circular } \\
\text { (b) }\end{array}$ & $\begin{array}{c}\text { Parabolic } \\
\text { (c) }\end{array}$ & $\begin{array}{c}\text { Elevation } \\
\text { (d) }\end{array}$ \\
\hline Exergy & $2 \%$ & 0 & 1 & 1 & 1 \\
\hline Collection Efficiency & $4 \%$ & 0 & 1 & 0 & 1 \\
\hline Optical Efficiency & $5 \%$ & 0 & 1 & 0 & 1 \\
\hline Ideal Conversion Efficiency & $3 \%$ & 0 & 1 & 0 & 1 \\
\hline Durable & $7 \%$ & 0 & 0 & 0 & 0 \\
\hline Concentration Ratio & $4 \%$ & 0 & 1 & 1 & 1 \\
\hline Use of Standard Parts & $5 \%$ & 0 & -1 & -1 & -1 \\
\hline Parasitic Loads & $2 \%$ & 0 & 0 & 0 & 0 \\
\hline Efficient Use of Land & $7 \%$ & 0 & 1 & 0 & 1 \\
\hline Tolerance of External Loads & $7 \%$ & 0 & -1 & 0 & 0 \\
\hline Reflectivity of Concentrator Elements & $7 \%$ & 0 & 0 & 0 & 0 \\
\hline Average Daily Shadow Efficiency & $6 \%$ & 0 & 1 & 0 & 1 \\
\hline Accurate Tracking & $6 \%$ & 0 & 1 & 0 & 1 \\
\hline Temperature Tolerance & $3 \%$ & 0 & 0 & 0 & 0 \\
\hline Heat Transfer Characteristics & $4 \%$ & 0 & 0 & 0 & 0 \\
\hline Specialist Coatings & $5 \%$ & 0 & 0 & 0 & 0 \\
\hline Compatible with Heat Transfer Fluid & $5 \%$ & 0 & 0 & 0 & 0 \\
\hline Pressure Tolerance (Fixed Receiver) & $4 \%$ & 0 & 0 & 0 & 0 \\
\hline $\begin{array}{l}\text { Half Acceptance Angle (Secondary } \\
\text { Concentrator) }\end{array}$ & $3 \%$ & 0 & 1 & -1 & 0 \\
\hline Cost per Exergy & $11 \%$ & 0 & 0 & 0 & 0 \\
\hline Total Score & & 0 & 7 & 0 & 7 \\
\hline Final Weighted Ranking & & 0 & 0.2772 & -0.0126 & 0.3215 \\
\hline
\end{tabular}

\section{Finalised design of selected concept.}

A final ELFR design using 8 mirror elements, each $250 \mathrm{~mm}$ wide and spaced $260 \mathrm{~mm}$ apart (10 mm gap), was chosen to satisfy the specified targets and limits. This formed a single LFR unit $4 \mathrm{~m}$ in length. A secondary compound parabolic concentrator (CPC) at the receiver aperture was also chosen to maintain the capture of rays from the collector extremity for changing element focal distances. Through the use of a CPC the width of the receiver's 
absorbing target was reduced, thus overcoming the disadvantage of using wide flat mirror elements. The target absorber was a $63.5 \mathrm{~mm}$ diameter pipe located at a height of $5 \mathrm{~m}$, with a truncated CPC so the receiver was not oversized. This provided the target concentration ratio of 30 as specified in the HoQ. To simplify the construction of a prototype the receiver was positioned at the maximum practical height of $2.5 \mathrm{~m}$, resulting in a receiver absorbing target width of $152.4 \mathrm{~mm}$; thus, three $63.5 \mathrm{~mm}$ pipes were selected (see Figure 5). The detailed design method for a CPC can be found in the literature and is therefore not presented here (Duffie and Beckman, 2006; Welford and Winston, 1989).

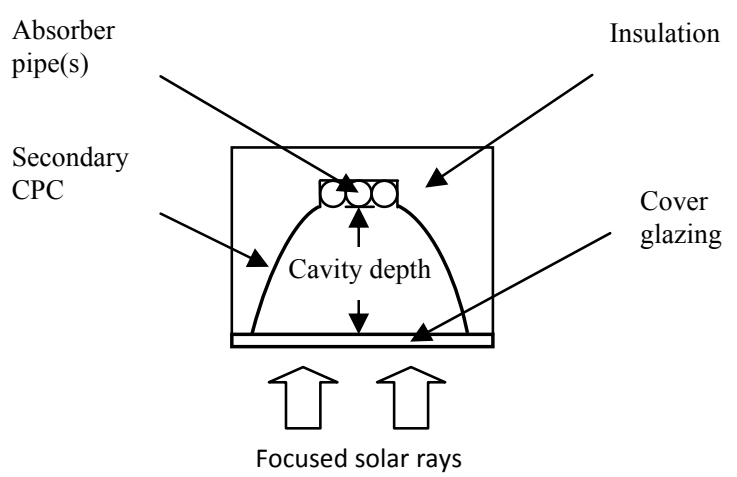

Figure 5: Schematic of an insulated receiver configuration with secondary CPC

\section{Detailed analysis of selected LFR against standard design}

Technical and financial criteria of the finalised ELFR were evaluated with reference to two equivalent Horizontal LFR designs with different spacing arrangements; 'H-constant' having mirror elements with a horizontal-constant spacing of $260 \mathrm{~mm}$ (the same spacing as the ELFR design), and 'H-variable' having horizontal-variable spacing such that the onset of shadowing among adjacent elements occurs at a solar transversal angle of $45^{\circ}$ (see Figure 6). Note that the wider mirror spacing of $\mathrm{H}$-variable requires a redesigned $\mathrm{CPC}$. The technical performance of each design was calculated from the maximum available power output (i.e. exergy) at the receiver's absorbing target surface. The financial factors considered were the 
land usage and the capital costs incurred from the LFR sub-components, which included the receiver, concentrator elements and frame.

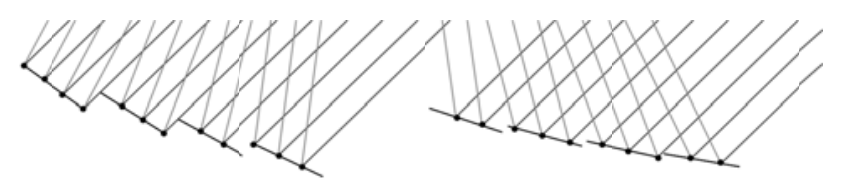

(a) ELFR

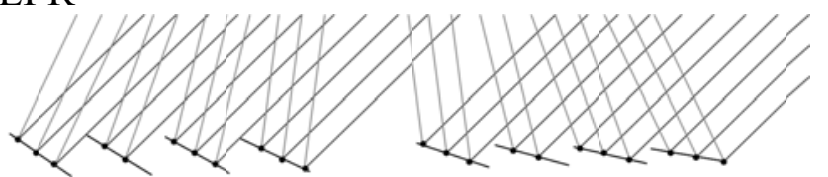

(b) H-constant

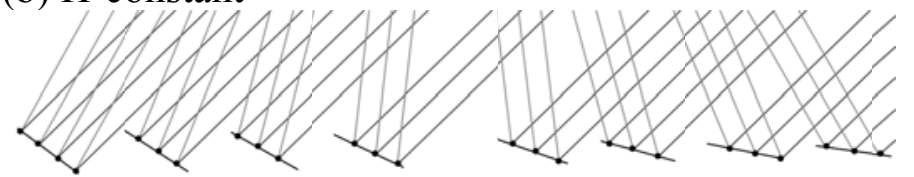

(c) H-variable

Figure 6: Mirror spacing arrangement for a (a) ELFR, (b) H-constant and (c) H-variable design for solar rays approaching at a transversal angle of $45^{\circ}$.

\subsection{Technical Analysis}

Achievable performance was predicted in this case for an LFR with specified location and mirror element arrangement with a north-south axis tracking orientation over a TMY for Gujarat. Since the focus of this study is on the collector design, the concept of exergy is used to provide details on the maximum available power output for a given operating absorber pipe surface temperature and ambient temperature. The exergy approach assumes an idealised Carnot cycle and therefore detailed assumptions that would be required for modelling a complete plant, such as piping layout, flow rate and choice of heat transfer fluid and heat engine, are not required. While a drawback of the exergy approach is that specific applications are not considered, exergetic analyses have still been widely adopted in the solar literature (Gupta and Kaushik, 2010; Singh et al., 2000; Tyagi et al., 2007). Exergy per unit 
area (given in W/m $\mathrm{m}^{2}$ of collector's total mirror area) as an hourly average in the TMY for an LFR is calculated from:

$E_{x, \text { out }}=Q\left(1-\frac{T_{a}}{T_{r}}\right)$

Where $Q$, the net heat transferred to the outer surface of the receiver's target, at a temperature $T_{r}$, which is given by:

$Q=Q_{i n}^{*}-Q_{\text {Loss }}$

where $Q_{\text {Loss }}$ is the heat loss to ambient (temperature $T_{a}$ ) and depends upon the receiver configuration. Thermodynamic calculations for two commonly employed receiver types (non-evacuated insulated pipe(s) with cover glazing, and evacuated tube) are given in the solar literature (Duffie and Beckman, 2006; Singh et al., 2010a). Heat transferred to the receiver, $Q_{i n}{ }^{*}$, is a product of the direct solar irradiance (DNI) on the collector's total mirror area, $A_{m}$, the optical efficiency at normal incidence, $\eta_{0}(0=\theta)$, and the incidence angle modifier (IAM), which accounts for the optical performance for varying solar ray incidence angles. Collector end losses are not considered.

$Q_{\text {in }}{ }^{*}=D N I \cdot A_{m} \eta_{0}(0=\theta) \cdot I A M$

The optical efficiency and the IAM includes factors such as the reflectance, transmittance, absorbance, intercept factor, shadowing, blocking, effective mirror aperture area, and incidence cosines for each mirror element. The individual mirror element elevation required 
throughout operation to remove shadowing, $e s_{n}$, can be approximated from the corresponding width, $W$, slope angle, $\theta_{n}$, and shift, $S_{n}$ (the horizontal gap between adjacent mirror elements).

$e s_{n}=\frac{W}{2}\left(\sin \theta_{n}+\sin \theta_{n+1}\right)-S_{n} \operatorname{Tan} \theta_{p}$

Where the sun's height is represented by the profile angle, $\theta_{p}$, which is the angle projected onto a plane perpendicular to the mirror tracking axis, formed between an approaching sun vector and the plane containing the axes of rotation of the mirrors (see Figure 7). Equations relating to sun-earth geometry calculations are not presented (Muneer et al., 2004; William et al., 2001). With a change in elevation an iterative process is required to calculate the correct slope angle. Depending upon the LFR geometry a narrow spacing arrangement may result in blocking of reflected rays from adjacent mirrors. The elevation to removing blocking is estimated by:

Approaching sun vector

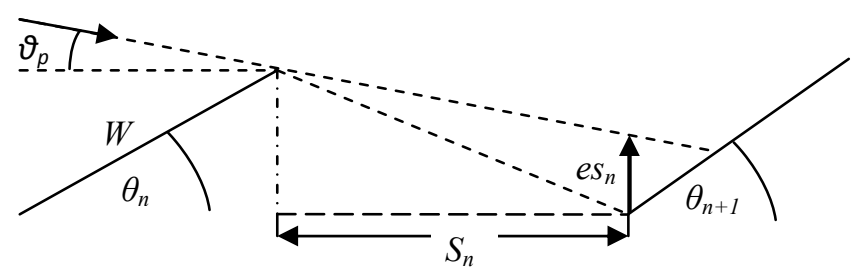

Figure 7: Elevation required to remove shadowing from an adjacent mirror element.

$$
e b_{n}=\frac{W}{2}\left(\sin \theta_{n+1}+\sin \theta_{n}\right)-\frac{S_{n} h}{\left(Q_{n+1}+\left(\frac{W}{2}\right) \cos \theta_{n+1}+S_{n}\right)}
$$

where $h$ is the height of the receiver and $Q_{n}$ is the horizontal distance from a mirror element to the receiver tower (see Figure 8). The tracking arrangement from sunrise to sunset for the ELFR is shown in Figure 9. 
Figure 8: Elevation required to remove blocking from an adjacent mirror element.

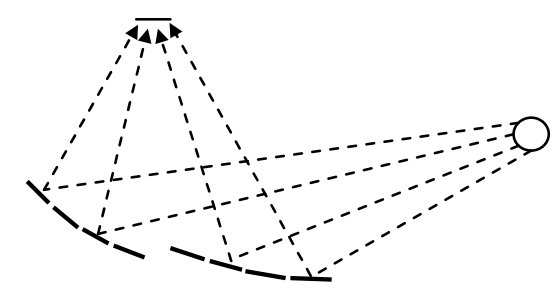

Figure 9: Tracking arrangement of the mirrors elements from sunrise to sunset for the ELFR.

The LFR shows a bi-axial dependency in relation to the direct solar incidence angle (Duffie and Beckman, 2006). A bi-axial $\operatorname{IAM}\left(\theta_{t}, \theta_{l}\right)$ was therefore used in this study, which includes an angle modifier for rays in the transversal plane $\operatorname{IAM}\left(\theta_{t}\right)$ (i.e. the vertical plane perpendicular to the rotation axes of the elements), and longitudinal plane $\operatorname{IAM}\left(\theta_{l}\right)$ (i.e. the vertical plane parallel to the rotation axes of the elements) (McIntire, 1982). Bi-axial IAMs are typically calculated using ray-tracing (Nixon and Davies, 2011). An estimate for the total optical efficiency is based on a product of $\operatorname{IAM}\left(\theta_{t}\right)$ and $\operatorname{IAM}\left(\theta_{l}\right)$, determined by projecting the solar incidence angle into the transversal and longitudinal planes respectively.

An incident angle dependent optical efficiency enables hourly stagnation temperatures, $T_{r, \max }$, to be calculated. The stagnation temperature is reached when heat loss to the surroundings becomes equal to incoming radiation. 